\title{
On the Estimation of the Degree of Damage of Wool Fibres by Means of the Alkali Swelling Treatment.
}

\author{
By Ishio Tsuiimoto*
}

\section{Introduction}

When wool fibres ate subjecled to merhanical actions during worsted spinning processes, it is important that we should be able to detect the slightest damage of fibres. Hitherto, the degrees of damage have been measured by means of comparatively complicated measurements of physical or chemical methods. As a curious method, the author tried to find out the latent change by measuring the time of recovery from supercontraction by the concentrated alkali swelling treatment of wool fibres, nearly free from the moisture content of fibres, by using a projecting microscope for this purpose. The experiment has confirmed that this method shows, conveniently and distinctly, a significant difference at $5 \%$ significance level in those fibres in the order of the processes. The longer the time required for recovery, the greater the degrees of damage. In addition to that, the author investigated to confirm the significant differences by the rate of strength, elogation and moisture content, and tried a molecular discussion.

\section{Experiment and Discussion}

He extracted the fat with the beuzol-alcohol solution on the sperimen that was sampled at random conveniently for certain reasons to get those into his possession in each process of simple woolen spinning. After specimens were washed with water and dried in the air, he sampled at random 1.5 fibres, one at a time, cut them into about $300 \%$ fibre length convenient for examination, and set them on the slide glass of the projecting mirroscope (230 times in magnification). He then immediately sel a drop of the concentrated alkali reagent on the fibre, while putting a stop watch to work at the same time. Secondly, he set a cover glass on the slide glass, and brought it inio focus on the screen. When the fibre was immersed in the reagent at

\footnotetext{
"Faculty of Engineering, Fukui Inuivrrsity
}

this time, it supercontracted quickly. After it showed maximum supercontraction in about $1 \sim 11$ min., its length began to recover to the original length, and it increased gradually in length and diameter. At this time he measured its time of recovery, which was calculated by the linear interpolation on the basis of the time of recovery to the original length from the time measuring variation of its length every minute. The measuring values were shown 2.74 (raw wool), 2.94 (fear naught), 3.20 (automatic feader), 3.26 (breast card), 3.34 (intermediate card) 3.70 (Finisher card, condenser card), 3.32 (mule) minutes (mean value in 15 times) in the order of the processes. During the measurement, because the fibre moved and bent at the earlier stage to begin supercontraction in the field of screen, it was copied by putting transparent cellophan paper on the screen and measured. Because of the necessity to keep as constant a temperature as possible on the slide glass during the measuring which followed, the slide glass was heated by putting an electric lamp directly on it before measuring. When the wool fibre was treated in the alkali solution, it showed X-ray photographic diagram to be different from $\%$ and $\%$ keratin type according to the reated condition, and it produced the so-called phenomenon of the supercontraction. In this experiment it showed a somewhat different phenomenon owing to the strong alkali reagent, i. e., after it produced supercontraction at the earlier stage, it recovered gradually to the original length and tended to in. crease somewhat in length more than the original length. On this phenomenon, molecular discussion will be summarized as follows:

When the fibre suffers the slightest damage, ils molecular main and side chain will be damaged, and produce the increase of noncrystallization region. When it is swollen by the reagent in this state, its molecular chain will be spread out on the direction to the side chain. The fibre micell arrangement will be disturbed, the crystallization region decreased, and the molecular chain 
will become more and more bent. Consequently the fibre increases in diameter, contracts in length and produces supercontraction. The relaxation time $\lambda$ is represented by the following formula :

$$
\lambda=A e^{r / K^{\prime} \boldsymbol{T}}
$$

Where $A$ is constant, $K$ is Boltzman constant, $U$ is energy. In case $U$ and $T$ have limiled values, the variation of crystallization region will be small, otherwise the variation of noncrystallization region will be increased. When the temperature is kept constantly as in this experiment, $U$ will show a certain degree of swelling. When the fibre is swollen, its intermolecular distance will increase temporarily, and its internal energy, decrease. In this case, it produces supercontrac- tion, but its molecular combination will be again promoted on account of the residual side chain, and the curve of molecular chain will relax.

Therefore, fibre length recovers to its original length, and the side chain will be somewhat damaged by the strong alkali reagent in the course of swelling time. The side chain will be worn and the main chain will be somewhat free. In case the fibre tends to become somewhat longer in length than the original length on account of rearrangement on the thermodynamicaly stable state, the increase of entropy of system will result. In addition to the above facts, the breaking strength, elongation and moisture content of fibres are shown in the following table:

\begin{tabular}{|c|c|c|c|c|c|c|c|c|}
\hline term & Process & raw wool & fear naught & $\begin{array}{l}\text { automatic } \\
\text { feeder }\end{array}$ & breast card & $\begin{array}{l}\text { intermediate } \\
\text { card }\end{array}$ & $\begin{array}{l}\text { finisher card } \\
\text { condenser card }\end{array}$ & mule \\
\hline $\begin{array}{l}\text { breaking } \\
\text { strength }\end{array}$ & $\int \mathrm{gr}$. & 13.4 & 12.9 & 12.8 & 12.5 & 12.3 & 11.7 & 11.5 \\
\hline $\begin{array}{l}\text { (mean value } \\
\text { in } 100 \text { times) }\end{array}$ & $\begin{array}{l}\text { standard } \\
\text { deviation }\end{array}$ & 2.20 & 2.24 & 2.02 & 2.35 & 1.96 & 1.77 & 1.89 \\
\hline $\begin{array}{l}\text { breaking } \\
\text { elongation } \\
\text { (ditto) }\end{array}$ & $\left\{\begin{array}{c}\% \\
\text { ditto }\end{array}\right.$ & $\begin{array}{l}34.5 \\
9.07\end{array}$ & $\begin{array}{l}36.3 \\
9.21\end{array}$ & $\begin{array}{c}36.6 \\
9.40\end{array}$ & $\begin{array}{l}38.4 \\
8.28\end{array}$ & $\begin{array}{l}39.5 \\
9.38\end{array}$ & $\begin{array}{c}41.3 \\
8.16\end{array}$ & $\begin{array}{l}42.0 \\
8.57\end{array}$ \\
\hline $\begin{array}{c}\text { moisture } \\
\text { content }\end{array}$ & $\%$ & 12.34 & 12.49 & 12.40 & 12.45 & 12.74 & 12.65 & 12.86 \\
\hline $\begin{array}{l}\text { (mean value } \\
\text { in } 10 \text { times) }\end{array}$ & ditto & 0.15 & 0.18 & 0.61 & 0.14 & 0.11 & 0.01 & 0.09 \\
\hline
\end{tabular}

